\title{
CAPITALISMO, ORGANIZAÇÃO DO TRABALHO E TECNOLOGIA DA PRODUÇÃO E SEUS IMPACTOS NA QUALIFICAÇÃO DA FORÇA DE TRABALHO
}

\section{CAPITALISM, ORGANIZATION OF THE WORK AND TECHNOLOGY OF THE PRODUCTION AND YOUR IMPACTS IN THE QUALIFICATION OF THE MANPOWER}

\author{
Jean Mari Felizardo ${ }^{1}$
}

\section{RESUMO}

Este artigo aborda um estudo teórico sobre capitalismo, organização do trabalho e tecnologia da produção e seus impactos na qualificação da força de trabalho. Para tanto, a metodologia utilizada foi de caráter exploratório, efetuando uma revisão de literatura sobre os temas e um confronto teórico entre as possibilidades compreensivas dos processos históricos. Constatou-se como considerações que há uma relação entre avanço tecnológico industrial (automação e robótica) e qualificação (conhecimentos técnicos específicos) para o posto de trabalho e que estão estritamente ligadas à dinâmica do gerenciamento e controle pelo capital.

PALAVRAS-CHAVE: Capitalismo - Qualificação profissional - Tecnologia industrial.

\section{ABSTRACT}

This article approaches a theoretical study on capitalism, organization of the work and technology of the production and your impacts in the qualification of the manpower. For so much, the used methodology was of exploratory character, making a literature revision on the themes and a theoretical confrontation among the understanding possibilities of the historical processes. It was verified as considerations that there is a relationship among industrial technological progress (automation and robotics) and qualification (specific technical knowledge) for the work position and that are strictly linked to the dynamics of the administration and control for the capital. 
KEYWORDS: Capitalism - Industrial technology - Professional qualification. 1 INTRODUÇÃO

Na lógica de produzir mercadorias, o capital busca intensificar a produtividade do trabalhador. Essa intensificação consiste na redução do tempo de trabalho necessário e prolongamento do tempo de trabalho não pago, em que o trabalhador continua a produzir (MARX, 1982).

$\mathrm{Na}$ fábrica, a divisão do trabalho em tarefas cada vez menores exige do trabalhador especialidade, domínio específico sobre determinada atividade. O trabalho, dividido em parcelas cada vez menores, implica na desqualificação do trabalhador. A parcelarização do trabalho corresponde à pulverização do saber científico e técnico do trabalhador.

A especialização e a fragmentação laborais foram intensificadas na vigência da organização do trabalho de base fordista-taylorista, predominante ao longo de quase todo o século $\mathrm{XX}$, pois a extração e o fracionamento do saber do trabalhador conheceram a sua forma mais aperfeiçoada com a gerência científica desenvolvida por Taylor (1970), e o fracionamento na execução do trabalho tornou-se rotina com o modelo organizacional adotado por Henry Ford, em suas fábricas automobilísticas.

O taylorismo e o fordismo são frequentemente utilizados como sinônimos, pois se complementaram e transformaram a forma de produzir e viver. A decomposição e a especialização de tarefas resultaram na diferenciação entre a força de trabalho especializada e não especializada.

A principal diferença entre as duas linhas é que o taylorismo decompõe tarefas e as distribui entre os trabalhadores individuais, ao passo que o fordismo recompõe as tarefas, "soldando" os trabalhadores individuais e fazendo deles máquinas humanas.

O taylorismo-fordismo supõe uma intervenção mínima do operário no processo de produção. A exigência de trabalhadores qualificados é restringida pela própria característica das atividades na produção, ou seja, a qualificação para realizar tarefas repetitivas e com pouco conhecimento agregado é mínima. 
A automatização eletromecânica dos processos no fordismo foi muito influenciada pelas ideias de Taylor (1970), de especialização dos operários e separação de "mãos e mentes" (quem pensa não executa e quem executa não pensa). Com a introdução da linha de montagem, o fordismo conseguiu garantir ao capital a determinação autoritária da cadência do trabalho, por intermédio da submissão dos trabalhadores à velocidade da linha de produção. Essa cadência do trabalho, fundamentada no rendimento individual, fez com que a extração da mais-valia ocorresse numa base mais ampla do que por meio da administração científica proposta por Taylor.

No início da década de 1970, desponta no cenário capitalista o modelo de produção desenvolvido inicialmente pela Toyota na década de 1940. Segundo Ohno (1997), um dos aspectos inovadores do toyotismo foi a introdução da necessidade de um trabalhador operar simultaneamente diferentes máquinas, característica muito comum na indústria têxtil. Este sistema de produção é decorrente também de uma necessidade econômica do Japão, após a Segunda Guerra, que precisava fazer crescer sua produção sem aumentar o contingente de mão de obra.

O surgimento do toyotismo não esteve associado a tecnologias industriais, pois a Toyota utilizava maquinário considerado ultrapassado em outros países. Neste caso, prevalecia a intensificação do ritmo de trabalho e o manejo de várias máquinas, eliminando os "tempos mortos".

Em diversos países capitalistas, o toyotismo foi recebido com euforia pelas empresas e associou-se ao cenário de tecnologias industriais presentes nas ditas economias de "primeiro mundo" e de algumas regiões do "terceiro mundo". Essa associação entre o toyotismo, tecnologias industriais e mobilidade do capital entre países ou regiões caracterizam a chamada acumulação flexível (HARVEY, 1994), apresentando alterações na organização do trabalho produtivo e rearranjos denominados de reestruturação produtiva (TEIXEIRA, 1998).

A reestruturação produtiva pode ser interna, ou seja, ocorre dentro da empresa, com modificações no ambiente de trabalho, oferecendo visualização e ao mesmo tempo isolamento dos trabalhadores em pequenas células; redução das gerências ou queda da verticalidade entre chefias e 
subordinados valorizados pelo taylorismo, entre outros. No plano externo, a reestruturação produtiva corresponde à mobilidade das empresas entre diferentes países ou entre as regiões de um mesmo país.

De acordo com Maranho (2008), um dos motivos da mobilidade entre regiões de um mesmo país ocorre em razão dos atrativos fiscais oferecidos por essas regiões. Esses atrativos são praticados pelo menos desde a década de 1960, mas a partir de 1990 se generalizaram, provocando o acirramento da guerra fiscal no Brasil, com disputa por novos investimentos.

Portanto, com base nesse constructo, esse artigo tem como objetivo apresentar um breve apanhado da literatura sobre capitalismo, organização do trabalho e tecnologia da produção e suas influências na qualificação da força de trabalho.

Para efeito do presente artigo, compreende-se como qualificação os conhecimentos específicos que o trabalhador tem sobre os processos produtivos e as máquinas para atingir metas. Há a referência mais ampla do termo qualificação no sentido de relação social entre os agentes sociais, que envolve a propriedade, significado e uso dos conhecimentos, saberes, competências, habilidades, necessários a uma profissão, ocupação ou atividade de trabalho, no entanto não será abordado essa relação neste estudo.

Em relação aos procedimentos metodológicos para a realização deste artigo, têm-se que o estudo é fundamentalmente qualitativo, de caráter exploratório, pois fez-se a busca do conhecimento teórico adequado por meio do estudo bibliográfico e confronto teórico entre as possibilidades compreensivas dos processos históricos.

\section{CAPITALISMO, ORGANIZAÇÃO DO TRABALHO E TECNOLOGIA DA PRODUÇÃO}

Nesta seção será apresentado o estudo teórico sobre capitalismo, organização do trabalho e tecnologia da produção e seus impactos na qualificação da força de trabalho. 


\subsection{A FORÇA DE TRABALHO E O CAPITAL}

A força de trabalho como mercadoria no mercado é prerrogativa de produção capitalista. É nele que a força de trabalho é negociada, ou seja, é ali que o trabalhador livre vê sua força de trabalho se transformar em mercadoria em contrapartida por algo chamado salário. Marx (1982) explica que existe o tempo de trabalho necessário - que é aquele que o salário paga - e o tempo de trabalho excedente - que permite ao empregador adquirir capital às custas do trabalhador. Isso cria a lei da mais-valia.

Em relação à caracterização da força de trabalho ao longo do tempo, Marx (1982) denominou de cooperação, manufatura e maquinaria, nos quais a propriedade, uso e significado do saber do trabalhador sofreram mudanças em razão da relação social historicamente desenvolvida entre trabalhadores e capitalistas. O saber do trabalhador ainda era de seu domínio na etapa caracterizada pela cooperação, apesar da divisão do trabalho já existente.

$\mathrm{Na}$ manufatura prevalece a especialização do trabalhador que se caracteriza pela

"[...] decomposição da atividade do artesão simples, a operação contínua manual, artesanal, dependendo, portanto da fôrça, da habilidade, rapidez e segurança do trabalhador individual, ao manejar seu instrumento" (MARX, 1982, p. 389).

Com a manufatura, esse saber ainda é de propriedade dos trabalhadores, assim como suas ferramentas. Esse saber e o próprio trabalhador são afetados. A repetição da mesma operação

"[...] transforma todo o seu corpo em órgão automático dessa operação. Por isso, levará menos tempo em realizá-la que o artesão que executa tôda uma série de diferentes operações" (MARX, 1982, p. 389).

Em razão dessa especialização, o trabalhador é um trabalhador parcial, mutilado, e o seu saber padece da mesma cisão e aparece-lhe como algo externo, estranho. Segundo Marx (1982, p. 413) "a divisão manufatureira do trabalho opõe-lhes as fôrças intelectuais do processo material de produção como propriedade de outrem e como poder que os domina". 
$\mathrm{Na}$ grande indústria ou maquinaria, a apropriação do saber historicamente acumulado passa ao completo domínio do capitalista. O trabalhador é destituído de seu saber, de suas ferramentas de trabalho e da decisão sobre o que, como, quando e para que produzir. O trabalhador é transformado de uma vez por todas em fator de produção, porque possui a capacidade de produzir mais do que o necessário para a sua subsistência, ou seja, detém a capacidade de produzir mais-valia.

O saber do trabalhador, na grande indústria, se transporta totalmente para as máquinas. Estas são seu instrumental de trabalho, mas não the pertencem. A maquinaria é instrumental de trabalho automatizado. Segundo Marx (1982, p. 484), na chamada grande indústria, em que estão presentes um complexo de máquinas autômatas, confirma-se a "[...] separação entre as fôrças intelectuais do processo de produção e o trabalho manual e a transformação delas em poderes de domínio do capital sôbre o trabalho".

O desenvolvimento tecnológico tornou-se marca expressiva e fator preponderante para o controle do processo produtivo e intensificação da produtividade, sendo que o capital buscou disciplinar, controlar a mão de obra a fim de garantir a apropriação do saber do trabalhador.

A qualidade humana de produzir mais do que o necessário para a subsistência é aproveitada ao máximo pelo sistema do capital. Esse excedente de trabalho é incrementado pelos rearranjos e controle da organização do trabalho, bem como pelo aperfeiçoamento dos meios de trabalho (maquinaria). $\mathrm{O}$ investimento em tecnologia industrial incrementa a produtividade, ou seja, o elastecimento do tempo de trabalho não-pago dos trabalhadores.

A utilização da maquinaria, conforme destacou Marx (1982, p. 424), tem como objetivo

"[...] baratear as mercadorias, encurtar a parte do dia de trabalho da qual precisa o trabalhador para si mesmo, para ampliar a outra parte que êle dá gratuitamente ao capitalista. A maquinaria é meio para produzir mais-valia". 
A concorrência intercapitalista impulsiona os donos dos meios de produção a investir em maquinaria cada vez mais moderna, elevando a taxa de mais-valia e aumentando a exploração e o ritmo das tecnologias industriais.

A obtenção de maior parcela do trabalho não-pago é sinônimo de acumulação do capital. A ciência e a tecnologia operativas na reprodução do capital, em geral, contribuem para reduzir o tempo de trabalho necessário e permitem ao capitalista usurpar mais tempo do trabalho que não foi (e nem será) pago ao trabalhador.

Ciência e tecnologia não são neutras, pois refletem as contradições das sociedades que as engendram, tanto em suas invenções, inovações e organizações quanto em suas aplicações. Na realidade, são formas de poder e de dominação entre grupos humanos e de controle da natureza (JAPIASSU, 1975). A ciência e a tecnologia transformaram-se em forças produtivas, agentes da própria acumulação do capital, aumentando a produtividade do trabalho humano (MARX, 1982).

Paralelamente à busca de tecnologias industriais, nos anos 1980, deflagrou-se o fenômeno da mundialização do capital (CHESNAIS, 1996, p. 15) como estratégia de acumulação do capital, caracterizando-se pela "centralização de gigantescos capitais financeiros (os fundos mútuos e fundos de pensão)", pois a rentabilidade dos fundos personifica o "novo capitalismo" de fins do século XX.

Chesnais (1996, p. 16) destaca que, com a ascensão do capital financeiro, surgiram formas de "aumentar a produtividade do capital em nível microeconômico, a começar pela produtividade do trabalho". Esse aumento baseia-se no recurso da apropriação da mais-valia, sem preocupação com as consequências sobre o nível de emprego e condições de trabalho ou com os mecanismos das altas taxas de juros.

A mundialização do capital pode promover a competitividade entre países e empresas e aumentar as exigências no mercado de trabalho no que se refere à elevação na produtividade, aumento da demanda pelo trabalhador qualificado e aumento de emprego relativo em serviços (terciarização) (CHESNAIS, 1996). 
No intuito da elevação da produtividade, as empresas industriais voltam-se à aquisição de novas tecnologias. $O$ avanço tecnológico, no interesse do capital, provocou desemprego em massa dos trabalhadores, bem como a ruptura dos processos que normalmente ocorrem nas organizações, de forma abrupta e vertical.

O princípio da concorrência intercapitalistas provocou a busca incessante por tecnologias industriais que visam aumentar a produtividade, bem como a quebra de fronteiras para que as empresas possam se deslocar à medida que surjam atrativos nacionais ou regionais mais interessantes para a acumulação do capital.

Esse acúmulo do capital e a sua continuidade não podem dispensar a revolução constante das forças produtivas. Neste ponto, o capital enfrenta sua maior contradição, porque precisa investir nas forças produtivas, principalmente em novas descobertas tecnológicas. Ao desenvolver as forças produtivas reduz significativamente o trabalho vivo, que cria valor. Porém, sem conseguir dar conta dessa contradição, o capital se reorganiza para implementar mudanças na forma de produção de mercadorias. Hoje, a forma predominante ainda é a grande indústria implementada outrora pelo taylorismofordismo e, mais recentemente, com a reestruturação produtiva.

Na linguagem utilizada pelas empresas, "quem não inovar ficará para trás" ou "quem não inovar vai desaparecer". A característica intrínseca da acumulação do capital é a anarquia da produção, que é impulsionada pela renovação permanente das forças produtivas, ou seja, da força de trabalho (manual ou mental) e de sua ferramenta (manual ou mental) de trabalho.

Portanto, a discussão sobre a qualificação do trabalhador geralmente vem acompanhada do fim do apogeu fordista e do anúncio de outras formas de organização trabalhista, ganhando espaço a discussão sobre a combinação do toyotismo e das tecnologias industriais.

A queda da produtividade e, consequentemente, a perda de competitividade (sobretudo nos Estados Unidos), e a forte reação sindical contra as práticas autoritárias do taylorismo-fordismo anunciavam o fim da sua supremacia como forma de organização do trabalho. 
A crise não é apenas do modelo de produção fordista, circunscrito à planta fabril, mas também uma crise no âmago do próprio sistema social que o fordismo traduzia. A crise do fordismo não logrou destruir o capital, estando intacta a essência desse sistema (ANTUNES, 1997; ARRAIS NETO, 2004; DRUCK, 1999).

De acordo com Frederico (1998), a reestruturação produtiva é resultado do esforço do capital para superar a crise da sua etapa fordista de organização do trabalho. O incremento das tecnologias industriais, a introdução de outras formas de gestão e controle da força de trabalho formam a ponta de um conjunto de estratégias utilizadas pelo capital para enfrentar essa crise.

A reestruturação de modernização tecnológica brasileira iniciou-se com a difusão dos círculos de controle de qualidade (CCQ), no final dos anos 1970. Essa estratégia fracassou, contudo, iniciando assim rápido avanço tecnológico (equipamentos), além de novas formas de organização do trabalho baseadas nas técnicas japonesas. As novas formas ensejam a entrada em cena do just in time (JIT), diminuição do lead time, controle estatístico de processo (CEP), sistema de manufatura celular, automação seletiva, entre outros.

Nos anos 1990, a modernização foi enfatizada de maneira firme. A reestruturação produtiva (sempre sob o paradigma capitalista ou empresarial) aumentou a qualidade e a competitividade, concentrando os esforços das empresas de maior capacidade competitiva na produção de produtos de maior valor agregado, repassando produtos de baixo valor agregado para terceiros (LEITE, 1994b).

De acordo com Machado (1994, p. 14), a mudança na base técnica da automação é relevante para as alterações nos processos de trabalho com importantes consequências para $\circ$ movimento de desqualificação e qualificação da força de trabalho.

Neste sentido, para que o trabalhador possa se incluir na sociedade de hoje, faz-se necessário que ele tenha um número mais elevado e complexo de capacidades. Além disso, é necessário saber como utilizar melhor as ferramentas disponíveis para a vida moderna. 
Leite (1994a) assegura que, para atender às exigências mais individualizadas de mercado, no melhor tempo e com qualidade, é necessário que a produção se sustente num processo produtivo flexível, que ofereça ao trabalhador formação para operar várias máquinas, a chamada polivalência. Isso representa um rompimento com o modelo fordista, no contexto do qual um trabalhador só tinha qualificação para operar um tipo de máquina. Desta forma, a mudança faz que os trabalhadores, sejam os especializados ou os já polivalentes e qualificados, se transformem em trabalhadores multifuncionais.

Paiva (1995) compartilha do mesmo pensamento de Leite (1994a), destacando o papel das tecnologias na mudança da qualificação. A sua análise destaca a proliferação das tecnologias microeletrônicas no trabalho e a sua extensão no cotidiano doméstico. A autora destaca as virtudes psíquicas flexíveis requeridas do trabalhador para adequar-se às exigências dessas tecnologias industriais.

\subsection{ORGANIZAÇÃO DO PROCESSO DE TRABALHO}

$\mathrm{Na}$ busca de entender a organização do processo de trabalho, a Sociologia redirecionou estudos para analisar como o capital organiza 0 consumo produtivo de sua força de trabalho. Isto porque, o objetivo da organização capitalista é controlar a produção e os trabalhadores, além de, visar ao aumento da produtividade e não ao desenvolvimento humano.

Também tem o desenvolvimento tecnológico como marca expressiva e fator preponderante para o controle do processo produtivo (capital e o trabalho). Sendo que o capital buscou disciplinar e controlar a mão de obra e garantir a apropriação do saber operário.

Com este desenvolvimento, teve-se a degradação significativa dos artesãos independentes. Lembrando que nesta época havia o trabalho cooperativo, no qual, os bens e serviços envolviam um grupo de pessoas trabalhando de forma colaborativa. Estes grupos geralmente eram coordenados pelas pessoas mais experientes, que eram chamadas de artesãos. As informações eram passadas do cliente para o artesão que acumulava as tarefas de venda, marketing, projeto, fabricação, assistência 
técnica, entre outras. Esta época poderia ter sido chamada de era do artesão, em que a preocupação com o ofício em relação às necessidades do cliente era grande, principalmente porque a sua não satisfação poderia comprometer o

nome da oficina e impossibilitar a continuidade de seus serviços na aldeia. Como o artesão executava todas as tarefas, da venda à assistência técnica, e trocava informações diretamente com seus ajudantes e com o cliente, as falhas de comunicação eram poucas e o resultado normalmente atendia às expectativas do cliente, no entanto, o trabalho artesanal tinha baixa produtividade.

Com a Revolução Industrial, as pessoas passaram a consumir os produtos que tinham à disposição, optando pela disponibilidade imediata e por preços menores, em detrimento de um serviço personalizado. $\mathrm{O}$ aumento de escala permitido pela padronização e mecanização contribuiu significativamente para popularizar o acesso aos bens e serviços, que antes ficavam restritos aos grupos mais abastados, o que deu origem à sociedade de consumo. Quanto maior se vislumbrava o mercado em potencial a ser atendido, maiores os incentivos para a modernização das oficinas, o que deu impulso ainda maior à Revolução Industrial.

A automatização ou mecanização dos processos foi muito influenciada pelas ideias de Taylor, de especialização dos operários e separação de "mãos e mentes" (quem pensa não executa e quem executa não pensa). O taylorismo originou-se da necessidade de criação de novos processos para as indústrias, sucessoras das oficinas dos artesãos. A oferta, que antes era menor que a demanda, passou a superá-la, com a Revolução Industrial. O trabalho, que fora realizado de forma cooperativa, passou a ser corporativo. Na maioria das vezes, deixou de representar algo sintético e abrangente (uma característica do trabalho cooperativo), passando a ser segmentado e desintegrado. A mudança do foco no cliente, para o foco na produção (em larga escala), ocasionou problemas nos projetos (LEITE, 1994a).

Com a capacidade de produção muito maior que a demanda, resultado da Revolução Industrial, entrou-se na era das vendas. A ênfase em vendas (para elastecer ao máximo a demanda) representou uma tentativa de encontrar mercado para o excesso de produção ou de capacidade produtiva. 
Os problemas no projeto, desenvolvimento e assistência técnica, que se tornaram frequentes na produção industrial, decorreram principalmente da perda do contato direto com o cliente e da fragmentação e especialização do trabalho, a ponto de impedir a identificação do trabalhador com o produto final.

Com tantos problemas nos produtos e com o excesso de produção, bom vendedor, nessa época, passou a ser aquele capaz de "empurrar o abacaxi" adiante, ou seja, para o cliente. Houve um enorme desenvolvimento das técnicas de vendas, que tiveram, no entanto, pouca eficácia na minimização da diferença entre a capacidade de produção e a demanda pelos produtos. A lógica do product out, ou seja, produzir tudo o que a capacidade da planta fabril permitisse, na certeza de que o mercado absorveria a produção foi rapidamente esgotada (LEITE, 1994a).

\subsection{PROCESSO DE REESTRUTURAÇÃO PRODUTIVA E AS NOVAS TECNOLOGIAS DA PRODUÇÃO}

Para Leite (1994a), o processo de reestruturação produtiva pelo qual o Brasil está passando atualmente, foi iniciado na década de 1950 por ocasião do crescimento acelerado da capacidade do setor produtivo de bens de capital e bens de consumo duráveis. A década de 1970, foi marcada pela grande expansão industrial e teve forte impacto no início nos anos de 1990, no governo Fernando Collor de Mello. Esse processo foi alavancado pelos novos padrões de competitividade internacional, bem como pelo conjunto de mudanças econômicas, políticas e sociais que ocorreram de forma simultânea no país. Observa-se, também, que a mão de obra utilizada nos processos de produção não era qualificada e com altos índices de rotatividade de pessoal (turnover).

O movimento operário e sindical reaparece na década de 1980 em função do processo de abertura política e cada um desses fatores alimenta e é alimentado pelos demais. As pressões internas para o aumento das exportações, provocadas pelo consumo interno e para o superávit da balança comercial modificam os parâmetros de competitividade das empresas em função dos novos padrões de qualidade. Esse fato foi responsável pela busca de tecnologias industriais para aumentar a eficiência das empresas e pela 
substituição de políticas repressivas de gestão de mão de obra para poder contar com a colaboração dos trabalhadores na busca da qualidade e da produtividade ${ }^{2}$. Nesse sentido, algumas empresas começam a implantar algumas técnicas japonesas de produção e novos equipamentos baseados na microeletrônica os quais foram sendo acompanhados por inovações de produto e de processo.

Leite (1994a) identifica três diferentes momentos do processo de modernização tecnológica:

1.início do processo - a difusão dos CCQ's - ocorrido no final dos anos de 1970 e no início dos anos de 1990 quando as propostas de inovação concentraram-se nos círculos de controle de qualidade CCQ's sem a preocupação da forma de organizar o trabalho ou investimento em novos equipamentos baseados na microeletrônica, bem como a falta de investimentos na qualificação do trabalhador. Destacam-se ainda os conflitos nas relações de trabalho baseado no autoritarismo no interior das empresas, constituindo uma barreira para 0 êxito das estratégias empresariais voltadas para 0 envolvimento dos trabalhadores nos processos de qualidade;

2.inovação tecnológica e organizacional - inicia-se em 1984-1985 a partir da retomada do crescimento econômico, após os primeiros anos da década de 1980 marcados por uma profunda recessão. Vale lembrar, também, que nesse período, o Brasil possuía a reserva de mercado para produtos de informática, surgindo várias empresas montadoras de computadores e que a partir do início da década de 90 começaram a desaparecer, em função da abertura do mercado. Isso não permitiu grandes avanços na inovação dos processos empresariais pois as pequenas e médias empresas não possuíam condições financeiras para investimento na melhoria da qualidade dos processos organizacionais. Apesar de todo o esforço das empresas em implantar novos métodos de produção, os indicadores 
de produtividade e de qualidade da indústria brasileira são os mais baixos do mundo;

3.os anos noventa - modernização sistêmica? - o terceiro e último momento se inicia nos anos de 1990 quando as empresas começam a concentrar seus esforços nas estratégias organizacionais e na adoção de novas formas de gestão de pessoas e na flexibilização do trabalho e o envolvimento dos trabalhadores com a qualidade e a produtividade. Dois fatores contribuíram para que as empresas investissem em uma estratégia inovadora e mais efetiva:

a) o aprofundamento da crise econômica a partir de 1990, em função da redução do mercado interno fez com que a produção fosse voltada para o mercado externo; b) a política econômica adotada pelo governo Collor que obrigou as empresas a melhorarem suas estratégias de produtividade e qualidade para poder concorrer internacionalmente. Duas frases ditadas por Fernando Collor de Mello marcaram esta passagem:

1. "quem não tem condições de competir não se estabeleçe", referindo-se aos empresários que estavam sempre reclamando das políticas governamentais;

2. "nossos carros são umas carroças", referindo-se às montadoras brasileiras de veículos quando o mesmo estava pilotando uma Ferrari em uma de suas viagens à Europa.

Destacam-se as mudanças ocorridas nos processos de gestão empresarial onde vários setores das empresas foram terceirizados, permitindo à empresa concentrar seus esforços no foco de seus produtos. Além disso, as empresas perceberam a necessidade de agregarem tecnologia a seus produtos e serviços como fator de competitividade e maior valor agregado. Outra característica desse momento é o esforço empresarial voltado para o 
treinamento em programas comportamentais e/o motivacionais com o intuito de despertar no trabalhador o espírito cooperativo em relação às estratégias gerenciais.

Por exemplo, no ano de 1998, aliança entre o Governo do Estado do Paraná e o SENAI, foi inaugurado o Centro Automotivo do Paraná (CEAPAR). O CEAPAR tinha como finalidade preparar mão de obra qualificada para ser contratada pelas montadoras instaladas no Estado. Além de cursos específicos para o setor automotivo, também contemplava módulo de aproximadamente 90 horas voltado para as questões educacionais e comportamentais. Os aspectos relacionados à perseverança, autoaperfeiçoamento, gestão consciente, honestidade e economia.

Segundo Enguita (1989a, p. 222)

"só podem ser pregadas como virtudes para os que vão incorporar-se ao trabalho na condição de autonomia. Qualquer dessas virtudes poderia ser pregada em um sermão dominical para todos os trabalhadores, mas para os trabalhadores elas são simplesmente impostas, ou se tornam inúteis, através da regulamentação estrita de seu trabalho".

Nesse período observa-se, também, um aumento da taxa de matrículas no Ensino Médio, conforme dados do Censo Escolar fornecidos pelo Instituto Nacional de Estudos e Pesquisas Nacionais (INEP, 2002), foram matriculados 8.192.948 alunos no Ensino Médio sendo que desse total 7.039.529 estavam matriculados na rede pública de ensino (federal, estadual e municipal), representando $86 \%$ e 1.153 .419 matriculados na rede privada de ensino, representando $14 \%$ das matrículas. Essas informações veem corroborar este momento, onde as empresas começaram a exigir formação educacional, no mínimo o Ensino Médio, para a melhoria da produtividade e qualidade dos produtos, processos e serviços.

Para Enguita (1989b, p. 224) está claro que

"a escola não propicia aos futuros trabalhadores as características
não cognitivas que podem chegar a esperar-se deles [...] mesmo que
se comece a ouvir falar no mundo do ensino de 'educação para a
iniciativa' - iniciativa que, curiosamente ou nem tanto, parece
restringir-se ao trabalho por conta própria [...]". 
Quanto à questão da estabilização da mão de obra, a tendência da diminuição das taxas de rotatividade ocorre, muitas vezes, com os processos de demissão em massa onde as empresas procuram demitir os trabalhadores: (i) pouco qualificados; (ii) com baixa escolaridade; (iii) idade mais elevada que apresentam maiores dificuldades para aprender e para adaptar-se aos novos conceitos de produção. Por outro lado, os sindicatos e trabalhadores têm encontrado muitas dificuldades em negociar com a classe empresarial as condições de trabalho. Para muitas empresas, os trabalhadores não encontram lugar para qualquer espécie de representação enquanto categoria política e social.

Para Leite (1994a), "a saída da crise atual dificilmente poderá realizar-se se a sociedade brasileira não se dispuser a negociar os modos de enfrentamento das dificuldades presentes".

Segundo Mattoso (apud LEITE, 1994a, p. 582)

essa negociação envolve um verdadeiro projeto nacional, objetivando articular a formação de um bloco social 'produtivo' capaz de enfrentar os desafios da Terceira Revolução Industrial (ou Revolução Tecnocientífica) e a gestação de um novo padrão de desenvolvimento.

O referido autor, também, diz que: "neste cenário, os desafios do presente são consideráveis e o trabalho - assim como as relações capital/trabalho - deverão passar por uma verdadeira revolução"(IDEM).

Também, a respeito das profundas transformações produtivas que vêm ocorrendo em escala global. Alguns anunciam suas virtudes, outros, por sua vez, denunciam suas mazelas. Fala-se no advento de novos padrões produtivos e, sem dúvida, o chamado modelo japonês se converteu numa das principais referências teórico-práticas. Contudo, é preciso reconhecer que, por diversos motivos, a conformação desse fenômeno no Brasil ainda é muito pouco conhecida.

Para Tumolo (2001), analisar o processo de reestruturação produtiva no Brasil é uma tarefa difícil e de grande envergadura. Primeiramente porque este é um fenômeno muito novo. De fato, Gitahy (1994, p. 123) afirma que "a difusão de tecnologias industriais e organizacionais na indústria brasileira 
começa em meados dos anos 70". Em segundo lugar, e pela razão já apontada, porque os estudos a respeito do processo de trabalho no Brasil e, principalmente, do processo de reestruturação produtiva também são bastante recentes. Para Catani (1995), nos anos 60 surgiram os primeiros trabalhos críticos e somente na década de 80 "observa-se a rápida proliferação de pesquisas sobre o processo de trabalho produzidos por sociólogos, mas também por economistas, engenheiros e historiadores" (CATANI, 1995, p. 25).

Assim se manifesta Catani (1995, p. 11),

\begin{abstract}
como ocorre em outras áreas, a compreensão de um determinado fenômeno é dificultada por dois tipos de problemas. O primeiro diz respeito à complexidade intrínseca do objeto de conhecimento que, no caso do processo de trabalho e das novas tecnologias, é imenso devido à rapidez e à diversidade das mudanças. O segundo problema concerne à dispersão de fontes e sua socialização limitada. Os dados e estudos não só são escassos, como também aqueles existentes não são facilmente encontráveis. Esforços de anos são materializados em relatórios, dissertações e teses que permanecem engavetados ou acessíveis a poucos. Artigos importantes são publicados em inencontráveis periódicos, análises e informações preciosas permanecem dispersas num cem número de publicações.
\end{abstract}

No que se refere aos vários aspectos dos processos de trabalho: introdução de novas tecnologias, organização e gestão do trabalho, qualificação/desqualificação, entre outros, é possível afirmar que a marca distintiva do chamado processo de reestruturação produtiva no Brasil é a heterogeneidade generalizada, que ocorre não só entre as empresas, mas também no interior delas (TUMOLO, 2001). No que diz respeito às relações de trabalho e às relações com as organizações sindicais, constata-se, ao contrário, uma congruência. Tumolo (2001) aponta a ocorrência da intensificação do ritmo de trabalho e da diminuição dos postos de trabalho e, ao mesmo tempo, uma busca das empresas no sentido de afastar e neutralizar a ação sindical, valendo-se de diversos mecanismos, desde a proposta de participação controlada dos trabalhadores até a perseguição e mesmo demissão sumária dos ativistas sindicais. Como também, há uma tendência de diminuição do preço do salário.

De uma maneira geral, a utilização de processos de trabalho tão diversificados tem surtido bons resultados para as empresas em termos de 
produtividade, competitividade e, portanto, lucratividade ${ }^{3}$. Em relação aos processos de reestruturação produtiva em curso no Brasil, configura-se num processo de modernização conservadora (TUMOLO, 2001).

Ferretti (1994, p. 9) afirma que um dos principais consensos entre os textos apresentados, amplamente ancorado em resultados empíricos, foi "a constatação da existência de uma enorme heterogeneidade de situações na implementação de processos de modernização". Assevera ainda que,

no Brasil, na opinião de diversos autores, o que estaria acontecendo mesmo seria a ampliação do leque de heterogeneidade da já diversificada estrutura produtiva brasileira, herdada da superposição de modelos diferentes, superposição essa intensificada a partir da década de 50 . Seria, em outros termos, uma "nova" heterogeneidade que estaria se sobrepondo à já existente (FERRETTI et al., 1994, p. 10).

Talvez seja por causa disso, vale dizer, da nova heterogeneidade que se sobrepõe à velha, que um dos comentadores do referido seminário chega a afirmar que, "no caso do Brasil, vimos nos últimos anos muito mais um processo de desestruturação do que propriamente de reestruturação" (OLIVEIRA, 1994, p. 214).

Analisando a literatura sobre o processo de reestruturação produtiva no mundo, Gitahy (1992, p. 14-5) observa que ela parece estar de acordo sobre alguns pontos:

a) que a crise atual é resultado do esgotamento do modelo de crescimento e de relações políticossociais que se afirmam internacionalmente após a Segunda Guerra Mundial, modelo este associado a uma determinada "matriz", "padrão" ou "paradigma" tecnoeconômico, ou de organização industrial;

b) que ela aponta para um processo de profunda reestruturação do aparato produtivo e das relações políticas e sociais e que sua análise não pode reduzir-se à dimensão econômica, mas tem que levar em conta as variáveis sociais, políticas e culturais; 
c) que para evitar o determinismo tecnológico é preciso desenvolver um enfoque que leve em conta a gênesis e a história da produção social da ciência e da tecnologia;

d) que nesse processo de mudança está emergindo um novo "padrão", "matriz" ou "paradigma" tecnoeconômico, cujo carro chefe é a incorporação de tecnologias intensivas em informação com base técnica na microeletrônica;

e) que este novo padrão acentua a tendência capitalista de elevar continuamente a composição técnica do capital, "que neste processo de reestruturação altera-se a divisão internacional do trabalho, assim como sua divisão social e sexual e modificam-se as relações sociais de produção e reprodução humana (estruturas familiares)".

Os resultados empíricos de estudos sobre os impactos da introdução de tecnologias microeletrônicas "apontam para um conjunto de efeitos heterogêneos e contraditórios que dependem do caráter não linear do processo de mudança tecnológica, e de sua articulação com a sociedade onde se verificam" (GITAHY, 1992, p. 15). A autora assinala ainda que a introdução e efeitos das novas tecnologias:

a) é diferenciada segundo as características específicas dos processos de produção em nível de país, região, setor econômico e mesmo diferentes segmentos de uma mesma unidade produtiva;

b) que a forma que assume a sua introdução vai depender das característica dos padrões de concorrência e das vantagens comparativas de diversos países, setores ou regiões;

c) que os efeitos de deslocamento de trabalhadores não ocorrem necessariamente no ponto de introdução das novas tecnologias; 
d) que a determinação das novas qualificações requeridas não dependem somente das características tecnológicas mas dos mercados de produtos e de trabalho, das estruturas organizacionais e das políticas sindicais;

e) que é necessário articular os efeitos diretos e indiretos desse processo de transformação, analisando as interrelações entre os mercados de trabalho formal e informal.

Em relação ao Brasil, Gitahy (1992, p. 19), defendendo a posição segundo a qual se delineia um novo paradigma produtivo, reconhece que "a discussão, tanto no que se refere à natureza do novo modelo, como o seu grau de difusão e quanto às suas implicações sociais, está longe de contar com o consenso dos estudiosos", pois poder-se-ia apresentar uma lista de pesquisas que apontam para a existência de um grande número de empresas dos mais diversos tamanhos, setores e regiões em processo de reestruturação inspirados principalmente no modelo japonês. Como contrapartida, provavelmente poderia listar outro grande número de pesquisas, descrevendo a hegemonia do taylorismo-fordismo nas empresas estudadas (GITAHY, 1992, p. 58).

Catani (1995) está de acordo com Gitahy (1992). O autor observa que a extraordinária produção sobre o processo de trabalho no Brasil ao longo da década de 80, com ênfases variadas, aponta para o caráter contraditório do avanço tecnológico, num quadro de relações de trabalho conservadoras e de movimento sindical sob tutela do Estado. O que transparece é que as transformações são feitas de forma irregular e contingente e que o controle capitalista raramente é ameaçado. $O$ despotismo permanece mesmo naquelas situações de aparente transformação do paradigma fordista. $O$ aperfeiçoamento das relações de trabalho foi parcialmente atingida apenas nas empresas nas quais os sindicatos são fortes e conseguem desenvolver ações autônomas (CARVALHO e SCHMITZ, 1990).

Apesar da crise, a economia brasileira tem revelado um surpreendente dinamismo. Mais do que a introdução de novas tecnologias 
físicas, o que se observa é a acelerada adoção de tecnologias de gestão. De forma criativa, o empresariado tem adaptado as diferentes estratégias de organização, compondo um heterogêneo, caótico, porém efetivo "paradigma de flexibilização".

Para Carvalho e Schmitz (1990, p. 26-7), os resultados dessa convivência são bastante claros: segmentação e diversificação dos trabalhadores e ampliação limitada e seletiva do mercado de trabalho. Em resumo, desigualdade crescente, mesmo com uma possível retomada do crescimento econômico.

Observando o conjunto de pesquisas que tem estudado o processo de reestruturação produtiva no Brasil, tem-se a impressão de que se olhar numa perspectiva geral e panorâmica, que se configura uma situação caótica daí, provavelmente, o comentário já supracitado de que parece muito mais um processo de desestruturação do que propriamente de reestruturação - o que praticamente inviabiliza o estabelecimento de relações e parece dificultar sobremaneira a apreensão do referido fenômeno.

Trata-se, portanto, da ordem do trabalho subordinada à ordem do capital e não da desordem do trabalho como vêm defendendo vários autores. Sob a ordem do capital, a ordem do trabalho não pode ser outra senão a necessária busca das formas mais eficientes de explorar a classe trabalhadora.

Desta forma, levando em conta as profundas diferenças e especificidades que guardam entre si, a busca do incremento da exploração da força de trabalho é o elemento central na constituição histórica das diversas fases do capitalismo, bem como de seus variados padrões de acumulação, desde os seus primórdios, na cooperação, até o keynesiano-fordista e o padrão que daí vem se originando.

No caso do Brasil, tal fenômeno e a decorrente degradação do trabalho vêm se realizando, no período recente, através da combinação de um conjunto de mecanismos, dentre os quais se destacam: intensificação do ritmo de trabalho, diminuição dos postos de trabalho e, consequentemente, aumento do desemprego, o que ocasiona um incremento substantivo da produtividade, concomitante com um processo de arrocho do salário médio. Além das 
pesquisas já anunciadas anteriormente, várias outras vêm demonstrando, com profusão de dados, a ocorrência desse fenômeno.

Cacciamali e Bezerra (1997, p. 31), observam que, a partir de 1992, depois da recessão do Plano Collor, quando caiu a produção industrial ao mesmo tempo que houve uma queda vertiginosa no número de pessoas ocupadas e nas horas pagas, a produção industrial voltou a crescer, "mas o emprego da mão de obra, não. Nesse caso prevaleceu o uso mais disseminado das inovações que excluem o trabalhador do processo de produção nas fábricas".

Por outro lado, enquanto cai acentuadamente o número de empregos, os ganhos acumulados entre 90 e 95 para a indústria de transformação são cerca de $48 \%$ quando observada a relação entre a produção industrial e o número de horas pagas na produção (CACCIAMALI e BEZERRA, 1997).

Com o intuito de contribuir para a identificação e o entendimento da componente tendencial do desemprego aberto no Brasil, ou seja, do desemprego estrutural, Portugal e Garcia (1997, p. 68) avaliam os dados da Pesquisa Mensal de Emprego (PME) do Instituto Brasileiro de Geografia e Estatística (IBGE) e chegam à conclusão que, "a partir do final da década de 80 e início da década de 90 , existe um aumento do desemprego estrutural no Brasil".

Baltar et al. (1996) fazem um estudo a respeito do mercado de trabalho e da exclusão social no Brasil e demonstram que, a partir dos anos 90, se configura um quadro macroeconômico que leva as empresas a adotarem "políticas defensivas de reestruturação", que tem implicado em devastadora eliminação de postos de trabalho. Para eles,

o padrão de desenvolvimento pós-30, fundado no processo de industrialização e em condições políticas muito particulares, gerou uma sociedade heterogênea, onde a pobreza e a exclusão social eram frutos do não enfrentamento do problema agrário e da reprodução de uma força de trabalho mal remunerada. A crise daquele modelo de desenvolvimento e, mais recentemente, das políticas liberais adotadas tem feito emergir uma nova forma de pobreza, que tem como foco a expulsão de massas de trabalhadores dos segmentos industriais e não-industriais urbanos mais estruturados (BALTAR et al., 1996, p. 106). 
Baseados nos dados da relação anual de informações sociais (RAIS) do Estado de São Paulo, Baltar e Proni (1996) fazem uma análise da rotatividade da mão de obra e da estrutura salarial do emprego formal e descobrem que, ao contrário do que se vem afirmando, as relações de trabalho se caracterizam pela flexibilidade e não pela rigidez, tendo em vista que, para grande parte do emprego formal, o vínculo de trabalho tem curta duração, transformando o operário brasileiro num trabalhador temporário. Para eles, "na prática, a regulamentação do trabalho no País não garante estabilidade no emprego e permite alta flexibilidade para o empregador contratar, usar, remunerar, e dispensar trabalhadores", o que acarreta graves efeitos sobre a estrutura salarial e sobre a qualificação da força de trabalho. Segundo os pesquisadores Baltar e Proni (1996, p. 141),

\begin{abstract}
desde 1980, o mercado de trabalho no Brasil tem apresentado uma proliferação de empregos fora do círculo dos estabelecimentos organizados e que não envolvem a assinatura da carteira de trabalho. A década de 1990 trouxe um agravamento da situação, na medida em que a abertura da economia favoreceu uma redução absoluta do emprego formal na indústria de transformação e na construção civil. Desse modo, não se trata apenas dos efeitos da estagnação econômica sobre o mercado de trabalho, mas do começo de uma reestruturação da economia que tem afetado a capacidade de geração de empregos. Essas mudanças, especialmente a diminuição do peso do emprego formal, podem inclusive ser interpretadas como um indício de uma tendência para uma maior desagregação da estrutura socioeconômica nas regiões mais desenvolvidas do país.
\end{abstract}

\title{
CONCLUSÃO
}

A partir do referencial teórico a respeito do tema abordado é perceptível que com o advento das tecnologias industriais há ocorrência de eliminação da força de trabalho de natureza estrutural. Dessa forma, a reinserção no mundo do trabalho de trabalhadores excluídos desse processo produtivo é dificultado pelo fato que ao longo do tempo a mão de obra operacional obteve qualificação somente para exercer funções específicas e não para a vida, num contexto amplo mais ligado a sua classe.

Também, apesar das novas tecnologias no processo produtivo e um melhor ambiente de trabalho, a força de trabalho sofre e tem problemas de 
saúde devido à falta de ajustes de ergonomia no decorrer de suas tarefas repetitivas, o que pode gerar uma incapacidade para o labor no decorrer dos anos e até o absenteísmo. Além disso, tem-se o fato do turnover que pode ser elevado pelo fato da simplificação das tarefas (corriqueiras e repetitivas) a serem executadas pela força de trabalho e pelo nível de stress elevado que o trabalhador é submetido

Aparentemente, as exigências demandadas pela força de trabalho parecem incoerentes com as novas exigências profissionais no que tange à capacidade de ter iniciativa e criatividade. Além das exigências de polivalência, a qual significa a capacidade que a força de trabalho tem para desempenhar várias atividades, proporcionando ampliação do grau e escopo de qualificação, contudo, tudo fica subjugado aos interesses das indústrias, o que aumenta ainda mais a precarização do sentido de qualificação no âmbito do trabalho e enfraquecimento da autonomia dessa classe. Portanto, a relação entre avanço tecnológico industrial (automação e robótica) e qualificação (conhecimentos técnicos específicos) para o posto de trabalho está estritamente ligada à dinâmica do gerenciamento e controle pelo capital.

Assim, mesmo reconhecendo que não se trata de uma comprovação definitiva, a análise acerca da reestruturação produtiva no Brasil sob a égide do capital, com base na literatura realizada, apresenta indícios claros de recrudescimento da degradação do trabalho no Brasil no final do século $X X$, como resultado necessário do processo de intensificação da exploração sobre a força de trabalho, que, se configura como característica determinante do padrão de acumulação de capital.

\section{REFERÊNCIAS BIBLIOGRÁFICAS}

ANTUNES, Ricardo. Adeus ao trabalho?: ensaio sobre as metamorfoses e a centralidade do mundo do trabalho. 4. ed. São Paulo: Cortez, 1997.

ARRAIS NETO, Enéas. Crise do fordismo ou crise do capital: a relação essência-fenômeno e as transformações do mundo do trabalho. In: ARRAIS NETO, Enéas; OLIVEIRA, Elenilce Gomes de; VASCONCELOS, José Gerardo (orgs.). Mundo do trabalho: debates contemporâneos. Fortaleza: UFC, 2004. 
BALTAR, Paulo E. de A.; DEDECCA, Claudio S.; HENRIQUE, Wilnês. Mercado de trabalho e exclusão social no Brasil. In: OLIVEIRA, Carlos A. B.; MATTOSO, Jorge E. L. (orgs.). Crise e trabalho no Brasil: modernidade ou volta ao passado? São Paulo: Scritta/Página Aberta/Cesit, 1996.

BALTAR, Paulo E. de A.; PRONI, Marcelo W. Sobre o regime de trabalho no Brasil: rotatividade da mão de obra, emprego formal e estrutura salarial. In: OLIVEIRA, Carlos A. B.; MATTOSO, Jorge E. L. (orgs.). Crise e trabalho no Brasil: modernidade ou volta ao passado? São Paulo: Scritta/Página Aberta/Cesit, 1996.

CACCIAMALI, Maria C.; BEZERRA, Lindemberg de R. Produtividade e emprego industrial no Brasil. In: CARLEIAL, Liana; VALLE, Rogério (orgs.). Reestruturação produtiva e mercado de trabalho no Brasil. São Paulo: Hucitec/Abet, 1997.

CARVALHO, R. de Q.; SCHMITZ, H. O fordismo está vivo no Brasil. In: Novos Estudos Cebrap. São Paulo: Cebrap, 1990, n. 27.

CATANI, Antonio David. Processo de trabalho e novas tecnologias. Porto Alegre: Editora da UFRGS, 1995.

CHASE, Richard B.; JACOBS, F. Robert; AQUILANO, Nicholas J. Administração da produção para a vantagem competitiva. Porto Alegre: Bookman, 2006.

CHESNAIS, François. A mundialização do capital. São Paulo: Xamã, 1996.

DRUCK, Maria da Graça. Terceirização: desfordizando a fábrica - um estudo do complexo petroquímico. São Paulo: Boitempo, 1999.

ENGUITA, Mariano Fernández. Do lar à fábrica, passando pela sala de aula: a gênese da escola de massas. In: A face oculta da escola: educação e trabalho no capitalismo. Porto Alegre: Artes Médicas, 1989a.

As contradições da relação entre escola e trabalho. In: $O$ mundo do trabalho. Porto Alegre: Artes Médicas, 1989b.

FERRETTI, C. J. et al. (orgs.). Novas tecnologias, trabalho e educação: um debate multidisciplinar. Petrópolis: Vozes, 1994.

FREDERICO, Celso. Prefácio. In: TEIXEIRA, F. J. S.; OLIVEIRA, M. A. (orgs.). Neoliberalismo e reestruturação produtiva: as novas determinações do mundo do trabalho. 2. ed. São Paulo/Fortaleza: Cortez/UECE, 1998.

GAROFALO FILHO, Emilio. Dicionário de comércio exterior e câmbio. São Paulo: Saraiva, 2004. 
GITAHY, Leda. Na direção de um novo paradigma de organização industrial? XVI Encontro Anual da Anpocs - GT. Processo de trabalho e reivindicações sociais. 1992.

Inovação tecnológica, relações interfirmas e mercado de trabalho. In: GITAHY, Leda (org.). Reestruturación productiva, trabajo y educacion en América Latina (lecturas de educacion y trabajo n. 3). Campinas: IG/Unicamp, Buenos Aires, RED CIID-Cenep, 1994.

HARVEY, David. A condição pós-moderna: uma pesquisa sobre as origens da mudança cultural. São Paulo: Loyola, 1994.

JAPIASSU, H. O mito da neutralidade científica. Rio de Janeiro: Imago, 1975.

LEITE, Márcia de Paula. O futuro do trabalho: novas tecnologias e subjetividade operária. São Paulo: Scritta, 1994a.

. Reestruturação produtiva, novas tecnologias e novas formas de gestão da mão de obra. In: OLIVEIRA, Carlos A. B. et al. (orgs.). O mundo do trabalho: crise e mudança no final do século. São Paulo: Scritta, 1994b.

MACHADO, Lucília Regina de Souza. Mudanças tecnológicas e a educação da classe trabalhadora. In: MACHADO, L. R. de S. et al. (orgs.). Trabalho e educação. 2. ed. Campinas: Papirus, 1994.

MARANHO, Eron José. O emprego formal na indústria de transformação paranaense segundo a intensidade tecnológica - 1995 a 2007. Curitiba: IPARDES, fev. 2008.

MARX, Karl. O capital: crítica da economia política. 7. ed., v. 1. São Paulo: DIFEL, 1982.

OHNO, Taiichi. O sistema Toyota de produção: além da produção em larga escala. Porto Alegre: Artes Médicas, 1997.

OLIVEIRA, Marco Antonio de. Debate. In: FERRETTI, Celso J. et al. (orgs.). Novas tecnologias, trabalho e educação: um debate multidisciplinar. Petrópolis: Vozes, 1994.

PAIVA, Vanilda. Inovação tecnológica e qualificação. Revista Educação \& Sociedade. São Paulo, n. 50, abr. 1995.

PORTUGAL, Marcelo S.; GARCIA, Lúcia S. Notas sobre o desemprego estrutural no Brasil. In: CARLEIAL, Liana; VALLE, Rogério (orgs.). Reestruturação produtiva e mercado de trabalho no Brasil. São Paulo: Hucitec/Abet, 1997. 
TAYLOR, Frederick Winslow. Princípios da administração científica. 7. ed. São Paulo: Atlas, 1970.

TEIXEIRA, Francisco J. S. Modernidade e crise: reestruturação capitalista ou fim do capitalismo? In: TEIXEIRA, F. J. S.; OLIVEIRA, M. A. (orgs.). Neoliberalismo e reestruturação produtiva: as novas determinações do mundo do trabalho. 2. ed. São Paulo/Fortaleza: Cortez/UECE, 1998.

TUMOLO, Paulo Sérgio. Reestruturação produtiva no Brasil: um balanço crítico introdutório da produção bibliográfica. Revista Eduação e Sociedade. 2001, v. 22, n. 77, pp. 71-99.

1 Doutor em Educação (UFC). Mestre em Tecnologia (UTFPR). Especialista em Logística Empresarial (PUCPR). Bacharel em Administração (UP). Coordenador e Professor no curso de Administração, Logística e de Marketing da Faculdade Estácio Radial de Curitiba. E-mail: jean_m_felizardo@yahoo.com.br.

2 Índice de saída para entrada. O valor monetário da saída dividido pelo valor monetário das entradas geralmente mede a produtividade do fator total. Alternativamente, a "produtividade do fator parcial" é medida com base em uma entrada individual e geralmente não é calculada usando os valores monetários (um exemplo seria unidades/pessoa) (CHASE et al., 2006, p. 127).

3 Medida do ganho proporcionado por este, em relação ao capital gasto na sua aquisição (GAROFALO FILHO, 2004, p. 160).

ARTIGO RECEBIDO EM 06.10.2010

ARTIGO APROVADO EM 21.10.2010 